\title{
Early Clinical Experience with Bleomycin in the United Kingdom in Series of 105 Patients*
}

\author{
K. E. HALNAN, N. M. BLEEHEN, T. B. BREWIN, \\ C. HOWLAND, P. B. KUNKLER, G. L. RITCHIE, \\ T. J. DEELEY, D. F. N. HARRISON, \\ E. WILTSHAW, I. D. H. TODD
}

below); the present paper reports preliminary experiences with the drug before these trials were initiated.

\section{Summary}

The results of treating a series of 105 patients (79 with advanced squamous cell carcinoma, 21 with advanced lymphoma, and 5 with miscellaneous tumours) with bleomycin are described. The drug was usually given as a single agent. Four patients with squamous cell carcinoma showed complete regression and there was partial regression in 25 . Side effects were frequent, particularly skin changes and stomatitis; death from pneumonitis occurred in one patient.

\section{Introduction}

Umezawa and his colleagues (1966) described bleomycin, a mixture of related antibiotic substances obtained from Streptomyces verticillus. It was found to have antitumour effects and, in particular, to be effective in squamous cell carcinoma without depressing the bone marrow. Earlier reports came from Japan (Ichikawa et al., 1969) and others more recently from Europe (O.E.R.T.C., 1970; Host et al., 1971; Rygard et al., 1971).

Although bleomycin causes little or no marrow depression it does have side effects. Transient pyrexia and cutaneous and mucosal effects are common, but the most serious though much less common expression of toxicity is pneumonitis (Jorgensen, 1971), which can be fatal.

Squamous cell carcinoma is frequently curable by surgery or radiotherapy or both but does not respond well to chemotherapy with existing drugs (see below). Although bleomycin is reported to be effective in squamous cell carcinoma without causing marrow depression there is a risk of potentially lethal lung complications, so particularly careful assessment of its unique action is required. The working party on bleomycin set up by the Medical Research Council is now conducting two controlled trials (see

*Report of the Medical Research Council's working party on bleomycin.

Institute of Radiotherapeutics, Glasgow

K. E. HALNAN, M.D., M.R.C.P., Director

T. B. BREWIN, M.R.C.P., F.F.R., Consultant in Radiotherapy

Middlesex Hospital Medical School, London W1

N. M. BLEEHEN, M.R.C.P., F.F.R., Professor of Radiotherapy

South Wales and Monmouthshire Radiotherapeutics Service, Cardiff

T. J. DEELEY, M.B., F.F.R., Director

Department of Laryngology and Otology, University of London WC1

D. F. N. HARRISON, M.D., M.S., Professor

MRC Statistical Research Services Unit, London W1N 4AI

C. HOWLAND, B.sc., Member of Staff

Department of Radiotherapeutics, University of Leeds, Leeds LS2 9JT

P. B. KUNKLER, M.D., F.R.C.P., Professor and Director of the Regional Radiotherapy Centre, Leeds

Royal Infirmary and Western General Hospital, Edinburgh

G. L. RITCHIE, F.R.C.S., F.F.R., Consultant in Radiotherapeutics

Chester Beatty Research Institute and Royal Marsden Hospital, London

E. WILTSHAW, M.D., Honorary Consultant in Chemotherapy

Christie Hospital and Holt Radium Institute, Manchester M20 9BX

I. D. H. TODD, M.R.C.P., F.F.R., Consultant in Radiotherapeutics

TABLE I-Age Distribution of Patients in Years

\begin{tabular}{|c|c|c|c|c|c|c|}
\hline $\begin{array}{l}\text { Age } . \\
\text { Number of patients }\end{array}$ & $\underset{9}{\leqslant 30}$ & $\begin{array}{c}31-40 \\
11\end{array}$ & $\begin{array}{c}41-50 \\
15\end{array}$ & $\begin{array}{c}51-60 \\
26\end{array}$ & $\begin{array}{c}61-70 \\
22\end{array}$ & $\frac{71}{22}$ \\
\hline
\end{tabular}

\section{Patients and Methods}

Records of 105 patients treated with bleomycin are available for study. There were 54 men and 51 women, their ages ranging from 15 to 92 (see Table I). Most patients suffered from squamous cell carcinoma in various sites, a smaller group had malignant lymphoma, and there were five patients with other tumours (see Table IV for details).

These patients all had advanced disease which had usually recurred after previous treatment with surgery, radiotherapy, or chemotherapy or any combination of these, and many were in rather poor general condition at the time of treatment.

\section{DOSAGE AND ADMINISTRATION OF BLEOMYCIN}

The drug is water-soluble and is given by injection either intravenously or intramuscularly. In this series the latter route has been preferred because of the ease of administration. Altogether, 74 patients were treated intramuscularly and 10 intravenously; in the remainder the route was not stated.

The doses adopted are based on Japanese and Danish experience (Ichikawa et al., 1969; Host et al., 1971). The usual dose was $30 \mathrm{mg}$ twice weekly either until signs of toxicity developed or until a total of $300 \mathrm{mg}$ had been given, whichever was lower, as there was an appreciable increase in the incidence of side effects above this dosage (Table II). However, a series of 12 patients (10 with cervical, 1 with oral, and 1 with penile carcinoma) received $15 \mathrm{mg}$ daily for 10 days. The lymphoma patients usually received appreciably lower doses, comparable to those reported by O.E.R.T.C. (1972).

The circumstances in which less than $300 \mathrm{mg}$ total dose was given are listed in Table III.

TABLE II-Number of Patients Receiving Bleomycin at Various Dose Ranges

\begin{tabular}{|c|c|c|c|c|}
\hline Dose range: & $0-100 \mathrm{mg}$ & $101-200 \mathrm{mg}$ & $201-300 \mathrm{mg}$ & $>300 \mathrm{mg}$ \\
\hline $\begin{array}{l}\text { Squamous cell carcinoma } \\
\text { and other solid tumour } \\
\text { patients } \\
\text { Lymphoma and } \\
\text { leukaemia patients }\end{array}$ & $\begin{array}{r}4 \\
10\end{array}$ & $\begin{array}{r}27 \\
9\end{array}$ & $\begin{array}{r}49 \\
2\end{array}$ & $\begin{array}{l}4 \\
0\end{array}$ \\
\hline
\end{tabular}

TABLE III-Circumstances in which Less Than $300 \mathrm{mg}$ Total Dose Given in 51 Cases
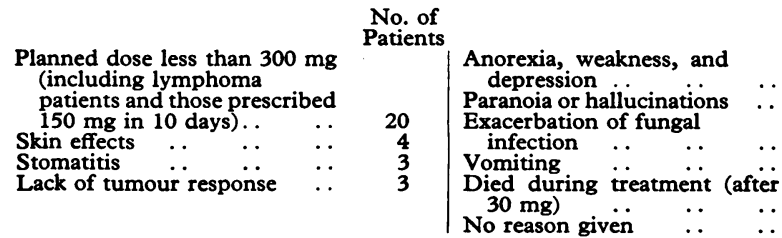

$\begin{gathered}\text { No. of } \\ \text { Patients }\end{gathered}$
2
2
1
1
1
14




\section{Results}

OBJECTIVE RESPONSE RATES

The results of treatment for all patients are presentedin Table IV.

TABLE IV-Composition of Series and Results of Treatment

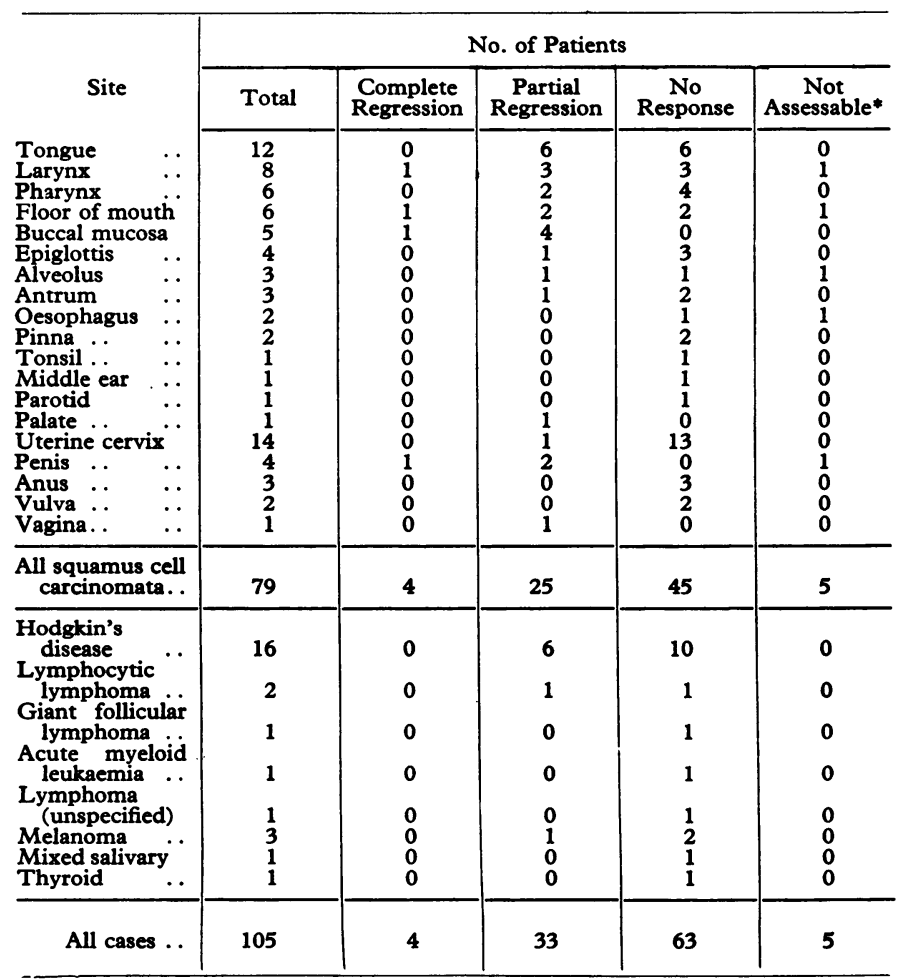

*Not assessable because of concurrent radiotherapy.

Four patients with squamous cell carcinoma were assessed as showing a complete clinical response. A man of 88 had a carcinoma of the larynx, recurrent after radiotherapy, which cleared completely after a dose of $300 \mathrm{mg}$ given in five weeks, but his tumour recurred in two months. A woman of 60 with carcinoma of the floor of the mouth, recurrent after hemimandibulectomy and treatment with methotrexate, responded completely to a dose of $315 \mathrm{mg}$ given in five weeks, and her response lasted four months. A man of 57 with carcinoma of the penis, treated initially by amputation, developed a fixed mass of nodes in the groin, which responded completely to a dose of $285 \mathrm{mg}$ in five weeks. He was given a second course of $300 \mathrm{mg}$ six weeks later after which he developed lung complications (to be described later) and the response was continuing at 18 months. Lastly, a woman of 63 with carcinoma of the buccal mucosa, recurrent after radiotherapy, responded completely to a dose of $270 \mathrm{mg}$ in four weeks; when last seen at hospital after three months she was well but she died after one year "with no obvious recurrences."

A partial response was recorded in 25 patients and in all but two lasted two months or less.

Forty-five patients with squamous cell carcinoma failed to respond at all, and in five an assessment could not be made because they had received concurrent radiotherapy (two of these patients showed a complete response and three a partial response).

No patient with lymphoma showed a complete response. One patient with lymphocytic lymphoma showed a partial response. Six patients with Hodgkin's disease showed some response, being sustained for five months in one case, but in two others the response was very dubious. These results are similar to those described by the Co-operative Group for Leukaemia and Reticulocytoses of the European Organization for Research on the Treatment of Cancer (O.E.R.T.C., 1972). One of the patients with melanoma showed a slight transient response but none of the other patients with miscellaneous tumours was helped.

\section{SIDE EFFECTS}

Side effects were frequent and are presented fully in Table V, although some mention of them has already been made in Table III.

TABLE v - Side Effects of Bleomycin Therapy

\begin{tabular}{|c|c|c|c|}
\hline Side Effect & & $\begin{array}{l}\text { No. of Patients in whom } \\
\text { Side Effect Noted }\end{array}$ & $\begin{array}{l}\text { No. of Patients in whom } \\
\text { Side Effect Severe Enough } \\
\text { to Interrupt Treatment }\end{array}$ \\
\hline $\begin{array}{lc}\text { Skin changes } & \ldots \\
\text { Stomatitis } & \ldots \\
\text { Fever } & \ldots \\
\text { Epilation .. } & \ldots \\
\text { Nausea and vomiting } \\
\text { Weakness } & \ldots \\
\text { Pneumonitis } & \ldots \\
\text { Miscellaneous } & \ldots\end{array}$ & \begin{tabular}{l|}
$\ldots$ \\
$\cdots$ \\
$\cdots$ \\
$\cdots$ \\
$\cdots$ \\
$\cdots$
\end{tabular} & $\begin{array}{r}50 \\
36 \\
35 \\
33 \\
16 \\
15 \\
2 \\
8\end{array}$ & $\begin{array}{l}4 \\
3 \\
0 \\
0 \\
1 \\
2 \\
1 \\
3\end{array}$ \\
\hline
\end{tabular}

On the whole these side effects tended to be more frequent and more severe at higher doses.

Skin changes usually took the form of erythema, especially over the pressure areas such as elbows, but also at other sitesfor example, the portals of previous $x$-ray treatment fields. This erythema sometimes proceeded to bulla formation and moist desquamation. The skin of the terminal phalanges tended to become thickened and, even when not visibly thickened, was often associated with sensory impairment or paraesthesia: Erythematous areas later became pigmented and there was sometimes pigmentation of palmar creases. Finger-nails also showed minor changes including the development of pigmented bands or streaks.

The mucosal changes in the mouth usually took the form of painful ulceration of the lips, buccal mucosa, or tongue and, clinically, this was often very reminiscent of a radiation reaction or of a methotrexate-induced stomatitis. Both skin and mucosal changes tended to clear within two weeks of discontinuance of treatment.

The miscellaneous side effects include pain at the injection site, intestinal disturbance, headache, hallucinations, paranoia, transient hypertension, and, in one case, exacerbation of fungal infection of the skin.

The most important side effects are lung complications which, though uncommon, may be fatal. The following case history is illustrative.

\section{Case Report}

A woman of 79 years with carcinoma of the buccal mucosa had previously had a carcinoma of the tongue treated by radium needle implant in 1947, followed by a block dissection of the neck in 1949, and a second radium needle implant for recurrent tumour of the tongue. In 1951 she had a hemiglossectomy and a further neck dissection but remained well thereafter, until a new carc.noma of the buccal mucosa developed in 1970 . She had a course of bleomycin given in $30 \mathrm{mg}$ doses twice weekly to a total of 300 mg which resulted in $75 \%$ regression of her tumour. In view of the response, a second course was started six weeks after completion of the first course. A further $120 \mathrm{mg}$ had been given when basal changes appeared in the lungs and progressed (Figs. 1, 2, 3) in spite of treatment with steroids, antibacterial agents, and antifungal agents.

The patient died 10 days after the first pulmonary changes were noted. At necropsy (we are indebted to Dr. M. Letcher for a note on the findings) no macroscopic tumour was seen and it was stated that "sections of the area showed simple ulcers of the mucosa, but no residual tumour." The lungs were described as follows: "The lung parenchyma showed areas where the alveolar 


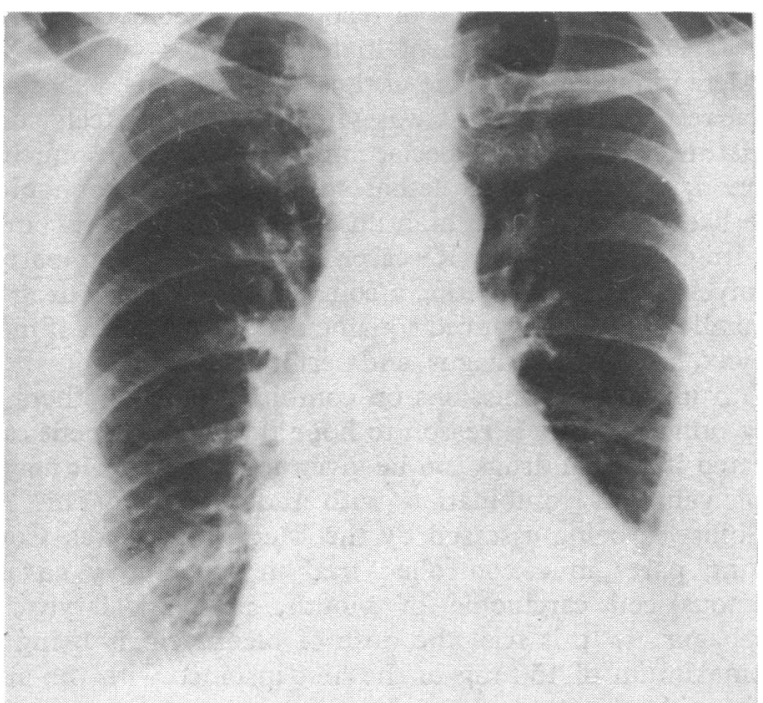

FIG. 1-Chest radiograph of 79-year-old woman at completion of first course of bleomycin.

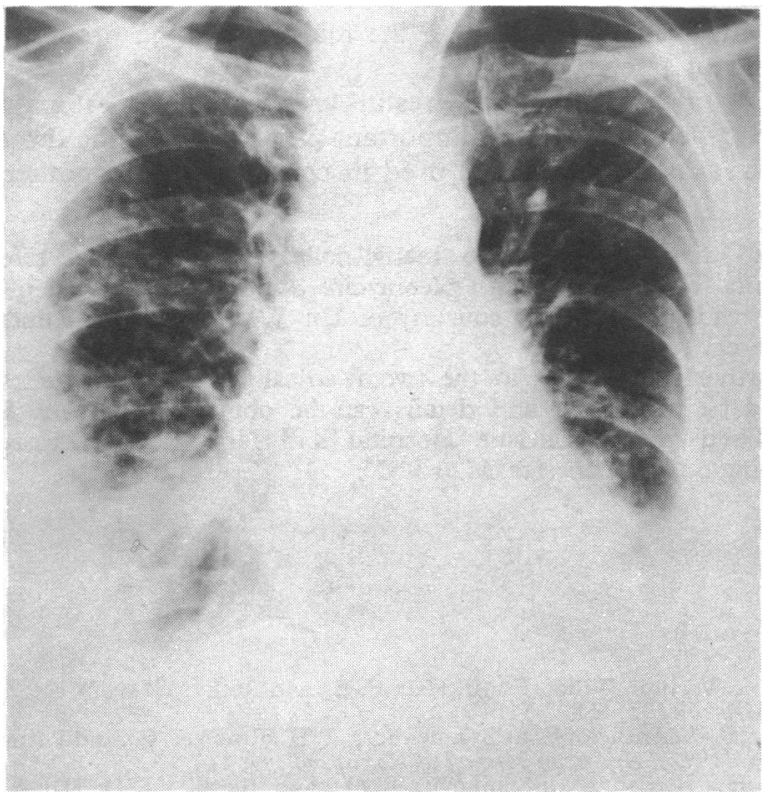

FIG. 2-Chest radiograph of same patient as in Fig. 1 when second course of bleomycin was stopped and pulmonary changes were appearing.

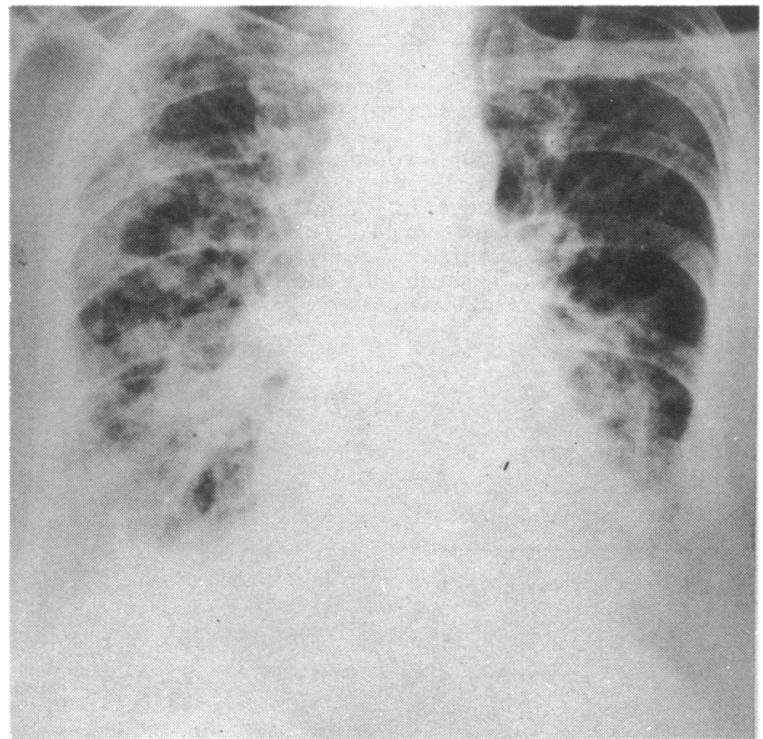

FIG. 3-Chest radiograph of same patient as in Fig. 1 three days before her death from pulmonary complications due to bleomycin. outlines were obliterated by dense tissue with a rubbery consistency. These tended to run along segmental bronchi with a fan-like distribution but small isolated areas were seen at the pleural edge and near lung septa."

The histological appearance of the lungs (see Fig. 4) was also described: "The rubbery zones were formed by young cellular fibrous tissue replacing the alveoli. Much of this appeared to be intra-alveolar in site-the engorged capillaries of alveolar walls surrounded the fibrous masses. Adjacent, more normal lung showed intra-alveolar oedema and quite prominent hyaline membrane formation. In areas alveolar lining cells were prominent and in some places there was proliferation of alveolar lining cells. No histological evidence of acute inflammation was present ... The appearances of the lungs quite closely resemble those described in busulphan lung, hexamethonium lung and uraemic lung."

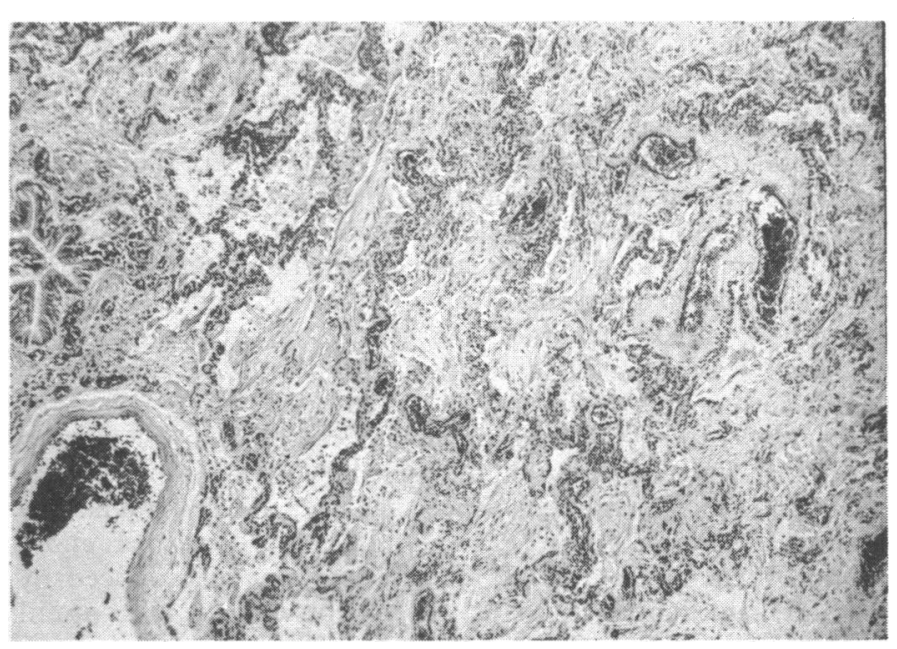

FIG. 4-Histological appearance of lung of patient dying from bleomycininduced lung disease. For detailed description see text.

This description is similar to that given by Jorgensen (1971) in his first patient, but the total dose of bleomycin given by Jorgensen was only $180 \mathrm{mg}$ in three weeks.

A further case history of a man of 57 with penile carcinoma referred to earlier as showing a complete response is described to show that lung changes apparently due to bleomycin may be reversible.

\section{Case Report}

In August 1970 a 57-year-old man had an amputation of the penis for a "verrucose squamous cell carcinoma," and by November

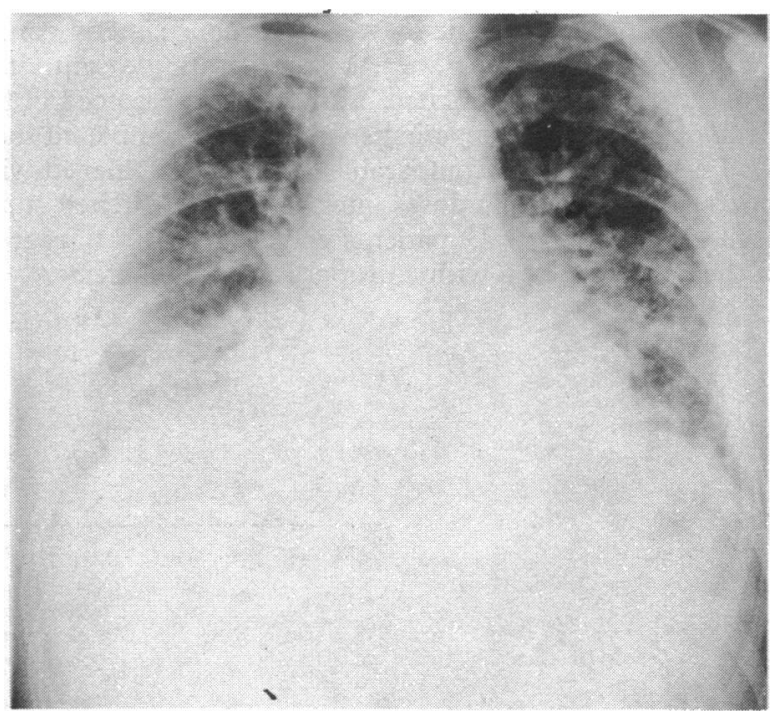
possibly due to bleomycin but who recovered. 
had developed a fixed mass of nodes in the groin. He had twiceweekly intravenous injections of bleomycin to a total dose of 285 $\mathrm{mg}$ in five weeks and this resulted in a complete response. In view of this a second course was given starting in late February 1971. The second course amounted to $300 \mathrm{mg}$ in five weeks, given intramuscularly, and when this was complete the patient had developed severe skin lesions on both elbows, arms, and hands; at this time his chest radiograph was clear. Four weeks after completion of his treatment he developed an illness with features suggesting bronchopneumonia (see Fig. 5). No lung biopsy was carried out. He was treated with prednisone at a dose of $60 \mathrm{mg}$ daily for 14 days, after which the dose was tailed off. When seen in July 1972 the patient was well and still in complete remission, having had no further treatment.

\section{Discussion}

Chemotherapy has been given to patients with squamous cell carcinoma of the head and neck with varying degrees of success since about 1960. Up until now the most commonly used drugs have been methotrexate and fluorouracil.

Fluorouracil was given together with irradiation by Foye et al. (1960) who claimed that the combination produced a greater antitumour effect than radiation alone, and in a randomized prospective trial Gollin and his colleagues (1972) reported a significantly increased survival in patients with carcinoma of the oral cavity treated with fluorouracil and radiotherapy, compared with those who received radiotherapy alone. Methotrexate in the treatment of head and neck cancer has been studied intensively by Bertino and his group (Papac et al., 1956; Kligerman et al., 1966; Mitchell et al., 1968). Regression can be produced by methotrexate alone in up to $50 \%$ of patients and the most useful regimen seems to be an intermittent one given as an infusion at a dose of $2 \mathrm{mg} / \mathrm{kg}$ over 24 hours followed by folinic acid ( $6 \mathrm{mg}$ intravenously at intervals of six hours for four doses after each infusion).

Unfortunately, the regressions are usually short-lived and rarely complete. The best that has been achieved with methotrexate is a mean duration of regression of five months with a range of three to eight months (Mitchell et al., 1968). It is in this context that the results of bleomycin treatment should be considered.

Published results of bleomycin treatment are varied and in most instances have arisen from uncontrolled observations. The drug may well have a place in the treatment of squamous cell carcinoma, but as yet it has not been evaluated against other forms of therapy. In our series of 55 cases of head and neck cancer there were only three patients with complete regression of their tumour. On the other hand, 20 of the 55 patients were given less than $200 \mathrm{mg}$ of bleomycin, usually because of side effects, and many of the patients were in a poor general condition. While the side effects were sometimes unpleasant, it is likely that if the investigators had been more experienced in the use of the drug most of the patients would have completed their course. These figures are comparable with those achieved with methotrexate given in high doses intermittently (Mitchell et al., 1968) where three out of 19 patients achieved $75-100 \%$ regression of their tumour, also with a proportion of side effects.
The quality and duration of response to bleomycin used as a single agent was poor except in four patinets who enjoyed a complete remission. In some of those experiencing a short-lived partial response the benefit was vitiated by side effects such as dermatitis, stomatitis, alopecia, and weakness. The much less common, but potentially lethal complication, pneumonitis is more likely to occur with high doses or with a second course of the drug. The Medical Research Council working party on bleomycin is now conducting a controlled trial of the drug used as a single agent in advanced squamous cell carcinoma of mouth, pharynx, larynx, oesophagus, and perineum.

With improved remissions on combination chemotherapy in many tumours there is reason to hope that more benefit can be expected if several drugs can be given together, and it may also be of value in combination with radiotherapy. This latter possibility is being assessed by the Medical Research Council working party in a controlled trial in moderately advanced squamous cell carcinoma of mouth, pharynx, larynx, and oesophagus. In this trial the dose of bleomycin is being kept to a maximum of $150 \mathrm{mg}$ in the first instance with the aim of keeping side effects to a minimum.

Bleomycin in advanced lymphoma is not of great value but it is sometimes effective, and the benefit can be obtained at a relatively lower dosage with a lower incidence of unwanted side effects. In this situation the marrow-sparing property can be a great asset.

Although in general these results are disappointing it may well be that bleomycin has an important part to play in the future as one of a number of drugs used in combination chemotherapy.

Our thanks are due to many colleagues who have referred patients for treatment with bleomycin. Supplies of bleomycin have been made available by courtesy of Dr. W. Simpson of Lundbeck Research.

Further participants in the two Medical Research Counc.l trials would be welcomed, and details can be obtained from Dr. I. D. H. Todd at the Christie Hospital and Holt Radium Institute, Withington, Manchester M20 9BX.

\section{References}

Foye, L. V., jun., Willet, F. M., Hall, B. E., and Roth, M. (1960). California Medicine, 93, 288

Gollin, F. F., Ansfield, F. J., Brandenburg, J. H., Romirez, G., and Vermund, H. (1972). American fournal of Roentgenology, 114, 83 .

Host, H., Berdal, P., Brennhovd, I. O., and Ekroll, T. (1971). Norske Tannlaegeforenings Tidende, 91, 714 .

Ichikawa, T., Nakaro, I., and Hirokawa, I. (1969). fournal of Urology, 102, 699.

Jorgensen, J. (1971). Ugeskrift for Laeger, 133, 342.

Kligerman, M. M., Hellman, S., von Essen, C. F., and Bertino, J. R. (1966). Radiology, 86, 247.

Mitchell, M. S. et al. (1968). Cancer Research, 28, 1088.

O.E.R.T.C. Clinical Screening Group (1970). British Medical fournal, 2,

O.E.R.T.C. Co-operative Group for Leukaemia and Reticulocytoses (1972). British Medical fournal, 1, 285.

Papac, R. J., Jacobs, E. M., Foye, L. V., jun., and Donohue, D. M. (1956). Cancer Chemotherapy Report, 32, 47.

Rygard, J. et al. (1971). Ugeskrift for Laeger, 133, 335.

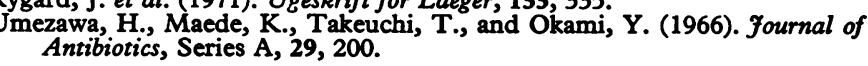

